\title{
A Rare Metastasis of Lung Carsinoma Detected with PET/CT
}

Yanik F*, Karamustafaoglu YA, Balta $\mathbf{C}$ and Yoruk $\mathbf{Y}$

Trakya University, School of Medicine, Thoracic Surgery, Edirne, Turkey

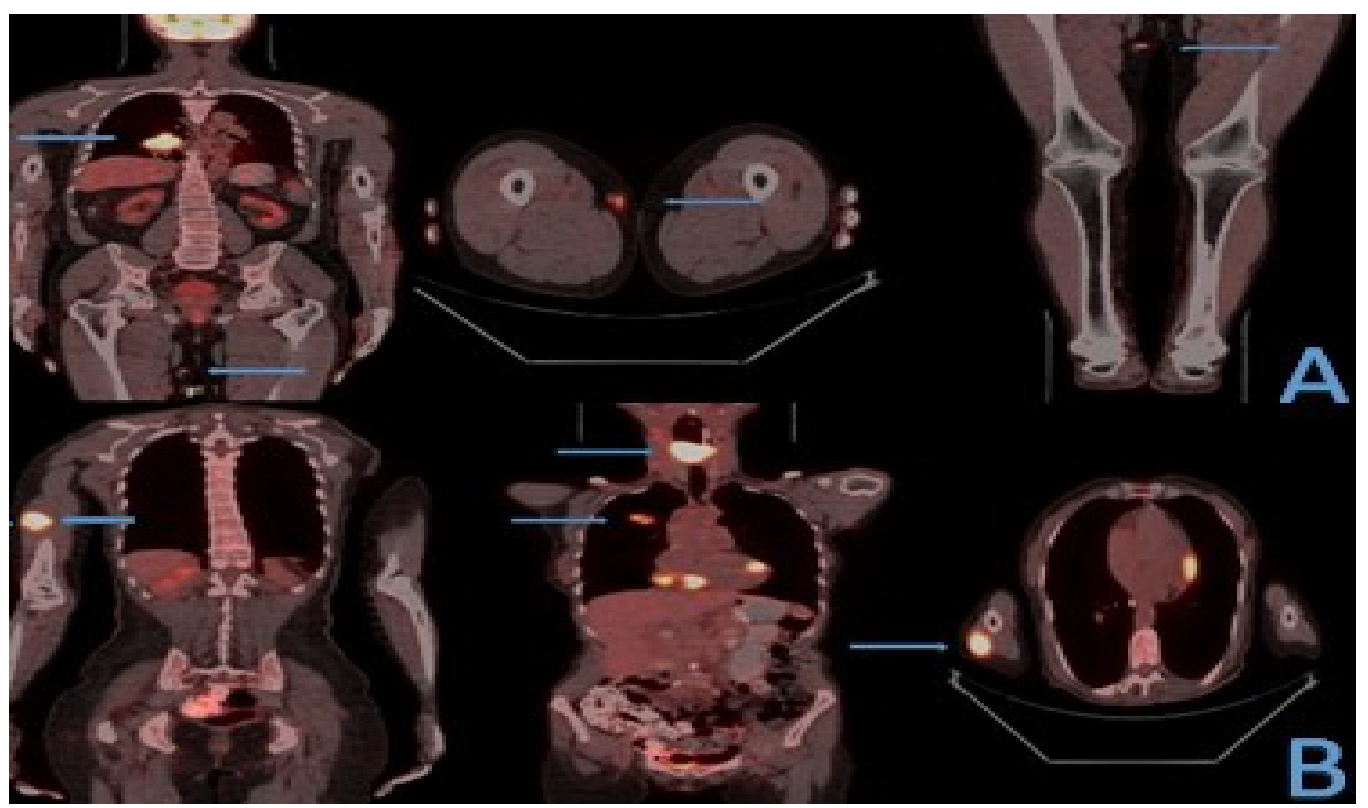

Figure 1: A) PET-CT images of the right centrally located lesion of the lung (SUVmax:12.7) and subcutaneous nodule medial to the right thigh (SUVmax:5) for case 1, marked with arrows. B) PET-CT images of the right upper lobe of lung (SUVmax: 7.3), the hypopharynx soft tissue mass (SUVmax:22.8) and the subcutaneous nodule of the right medial arm (SUVmax:17.8) for case 2, marked with arrows.

\section{Case 1}

A 61-year-old male case presented with cough and swelling of thigh. He had a history of smoking at 30 packets/year. Chest $\mathrm{X}$-ray and tomography showed $5 \mathrm{~cm}$ spicule contour mass in the right lower lobe of the lung. Positron Emission Tomography (PET) detected two malignant appearance; on the right lung SUVmax value:12,7 and SUVmax: 5 on the subcutaneous nodule of the right medial thigh (Figure 1A). Tumor infiltration was detected in the right lower lobe bronchus on the fiberoptic bronchoscopy and the biopsy result was reported as squamous cell carcinoma. Subcutaneous lesion biopsy was performed with histopathological finding of squamous cell lung carcinoma metastasis. The case was considered inoperable. He was treated with concomitant chemo-radiotherapy and without any problem of the case in the 10th month of follow-up period.

\section{Case 2}

A 59-year-old female case presented with dyspnea, hoarseness, weight loss and swelling of right arm. She had a history of smoking at 25 packets/year. Chest X-ray and tomography showed $3 \mathrm{~cm}$ central mass in the right upper lobe of the lung and 4 $\mathrm{cm}$ soft tissue mass in the hypopharynx. Positron Emission Tomography (PET) detected three malignant appearance; on the right upper lobe of lung SUVmax value:7.3, on the hypopharynx soft tissue mass SUVmax value:22.8 and on the subcutaneous nodule of the right medial arm SUVmax: 17.8 (Figure 1B). Subcutaneous lesion biopsy was performed with histopathological finding of lung carcinoma metastasis. The case was considered inoperable. First tracheostomy opened to protect the airway and nasogastric tube fitted for feding. She was treated with chemotherapy and without any problem of the case in the 3th month of follow-up period.

*Corresponding author: Fazli Yanik, Trakya University, School of Medicine, Thoracic Surgery, Edirne, Turkey, Tel:+90 (284) 23642 05; E-mail: fazliyanik@hotmail.com

Citation: Yanik F, Karamustafaoglu YA, Balta C, Yoruk Y (2017) A Rare Metastasis of Lung Carsinoma Detected with PET/CT. Int J Clin Med Imaging 3: 541. doi:10.4172/2376-0249.1000541

Copyright: (C) 2017 Yanik F, et al. This is an open-access article distributed under the terms of the Creative Commons Attribution License, which permits unrestricted use, distribution, and reproduction in any medium, provided the original author and source are credited. 
Metastasis to skin-subcutaneous tissue is rarely detected in lung cancer. The detection of these metastases and the treatment approach are difficult and this is an important factor that alters survival. Autopsy series have detected subcutaneous metastases in $0.75-9 \%$ of patients who died from metastatic lung carcinoma [1,2]. A retrospective study in 2012 indicated that $2.8 \%$ of 2130 patients with advanced non-small cell lung cancer (NSCLC) showed cutaneous metastases as an initial presentation [3]. The most common histologic type of carcinoma of the lung that metastasizes to skin-subcutaneous tissue is adenocarcinoma followed by squamous cell, small-cell and large-cell carcinoma [4]. In very rare cases, soft tissue metastasis may occur at the same time or before the primary cancer has been detected. The most frequently reported locations of subcutaneous metastases include the back, chest wall, abdomen, thigh muscles, ileopsoas muscle and paraspinous muscles. The metastases often may occur by a hematogenous route or via lymphatics [2,4]. Despite the combination of radiotherapy and chemotherapy, patients with lung cancer with cutaneous metastases have a poor prognosis; median survival of patients with lung cancer metastases is 3-6 months [5]. Histopathologic sampling should be performed and all lung cancer should be considered to be metastasis in skin-subcutaneous tissue lesions detected in the case of suspicion. Local subcutaneous biopsy to be performed makes it possible to reach definite histopathologic diagnosis and to carry out genetic studies thanks to large biopsies to be taken.

\section{References}

1. Baines MS (1991) Surgical treatment of lung cancer. Chest 100: 826-37.

2. Perisano C, Spinelli MS, Graci C, Scaramuzzo L, Marzetti E, et al. (2012) Soft tissue metastases in lung cancer: a review of the literature. Eur Rev Med Pharmacol Sci 16: 1908-1914

3. Song Z, Lin B, Shao L (2012) Cutaneous metastasis as a initial presentation in advanced non-small cell lung cancer and its poor survival prognosis. J Cancer Res Clin Oncol 138: 1613-1617

4. Mollet TW, Garcia CA, Koester G (2009) Skin metastases from lung cancer. Dermatol Online J 15: 1.

5. Triller Vadnal K, Triller N, Pozek I, Kecelj P, Kosnik M (2008) Skin metastases of lung cancer. Acta Dermatovenerol Alp Panonica Adriat 17: $125-128$. 